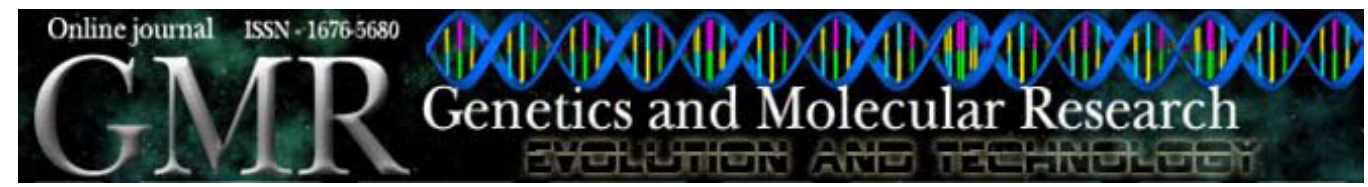

\title{
Conserved baculoviral ORFs 10 and 14 from Bombyx mori multiple nucleopolyhedrovirus
}

\author{
S.A. Santos ${ }^{1}$, J.L.C. Silva ${ }^{1}$, V.A. Balani ${ }^{1}$, F.A.V. Seixas ${ }^{2}$ and M.A. Fernandez ${ }^{1}$ \\ ${ }^{1}$ Departamento de Biologia Celular e Genética, \\ Laboratório de Organização Funcional do Núcleo, \\ Universidade Estadual de Maringá, Maringá, PR, Brasil \\ ${ }^{2}$ Laboratório de Química do Centro de Tecnologia, \\ Universidade Estadual de Maringá, Campus Umuarama, Umuarama, PR, Brasil \\ Corresponding author: M.A. Fernandez \\ E-mail: mafernandez@uem.br; aparecidafernandez@gmail.com
}

Genet. Mol. Res. 9 (1): 457-470 (2010)

Received December 3, 2009

Accepted January 5, 2010

Published March 16, 2010

\begin{abstract}
ORFs 10 and 14 from Bombyx mori multiple nucleopolyhedrovirus (BmMNPV) were amplified, cloned and sequenced. Nucleotide analysis of these genes and those of other baculoviruses showed that these genes are highly conserved. The p10 protein from BmMNPV ORF10 has 70 amino acid residues similar to that of the four other known BmNPV strains. The BmMNPV ORF14 alignment showed a higher identity with the nucleopolyhedrovirus ORF14 from the baculovirus BmNPV and from Autographa californica multiple nucleopolyhedrovirus. The BmMNPV ORF14 protein has a putative transmembrane domain in the C-terminal region, which is similar to that of other baculoviruses. A phylogenetic analysis showed that BmMNPV ORF14 protein has higher similarity with BmNPV ORF14 and ORF23 of A. californica multicapsid nucleopolyhedrovirus (Ac23). We conclude that proteins produced by ORFs 10 and 14 from BmNPV and BmMNPV are highly conserved in NPVs and MNPVs. The high degree of conservation among members of these genera indicates the importance of these proteins, which could mean an important function that is active throughout the infection cycle.
\end{abstract}

Key words: Baculovirus; BmMNPV; ORF10; BmMNP; ORF14 Bombyx mori multiple nucleopolyhedrovirus subgroup 


\section{INTRODUCTION}

Baculoviridae are a diverse virus family that is pathogenic to the Lepidoptera order. This family is subdivided into two genera, Nucleopolyhedrovirus (NPV - nuclear polyhedrosis virus) and Granulovirus (granulosis virus), which are differentiated by the morphology of occlusion bodies. The viruses from Nucleopolyhedrovirus genera may have only a single nucleocapsid per virion (single nuclear polyhedrosis virus) or more than one nucleocapsid per virion (multiple nuclear polyhedrosis virus - MNPV) (Blissard, 1996).

The baculovirus genome is composed of a circular double-strand DNA that is surrounded by a protein capsid (Hayakawa et al., 2000). Thus, this shape consists of the infective form of the virus (nucleocapsid). The virions, during the infection cycle, can assume two different forms: one of them is responsible for the systemic infection, cell to cell, inside of the insect body, referred to as the budded virus; the second form, called the polyhedra-derived virus, that has occluded multiple nucleocapsids in a crystalline matrix composed mainly of polyhedrin, responsible for the horizontal transmission of the disease, from insect to insect (Gomi et al., 1999; Acharya et al., 2002; Rahman and Gopinathan, 2003). These two different phenotypic forms have diverse functions in the infection cycle.

The infection caused by nucleopolyhedrovirus is the main reason of economic losses in sericulture, a very important agroindustrial activity in Brazil and in the world. The isolation of a Bombyx mori multiple nucleopolyhedrovirus (BmMNPV) subgroup in Brazil was described by Brancalhão (2002) in silk larvae collected in Paraná State, Brazil. This type of virus is highly virulent, since several nucleocapsids per virion can be found (Torquato et al., 2006). Contaminated food (Morus alba L.) is the main contamination source for silkworms (Watanabe, 2002).

When the virus reaches the middle intestine of the insect, it is submitted to a higher alkaline $\mathrm{pH}$ (approximately 11), which dissolves polyhedrin, releasing the virions in the digestive lumen. In the first hour of infection, the virions pass into the middle intestine epithelial cells via membrane fusion (Horton and Burand, 1993), transferred to the nucleus, where they lose the protein envelope and release the DNA, during the period of $1 \mathrm{~h}$ after infection.

This virus is easily spread by hemolymph, feces, and larval regurgitation, and its transmission could occur also by vertical transmission by its progeny (Khurad et al., 2004). The baculovirus produces some proteins that help in the infective process, such as GP64 (Garry and Garry, 2008). There are also other proteins that are produced during the late phase of infection, such as chitinase and cysteine protease, which probably act in the insect's tissue dissolution, disrupting the larval cuticle, and release the polyhedra (Hawtin et al., 1997).

Nucleopolyhedrovirus infection has become one of the most important economic issues for sericulture in tropical regions. Until now, there is no therapeutic agent available to control virus infection, and prevention against insect infection is the only current possible solution.

Recent studies on Bombyx mori have been carried out in search of pure strains and resistant or tolerant hybrids to nucleopolyhedrovirus, since the infected insects demonstrate a series of morphological and behavior changes, and consequently, they end up dying after a few days (Rahman and Gopinathan, 2003; Yao et al., 2003).

The aim of this study was to investigate if BmMNPV open reading frames (ORFs) 10 and 14 could be correlated to this baculovirus phenotype. This study was carried out by gene sequencing and analysis of structural parameters of their respective proteins. 


\section{MATERIAL AND METHODS}

\section{Biological material and baculovirus infection}

The experiments were carried out with Bombyx mori hybrids from Fiação de Seda BRATAC S/A, which produces larvae for economical purposes in Paraná State, Brazil. One hundred third-instar larvae were maintained in the laboratory with the same management in relation to feed (fresh mulberry leaves) and under controlled environmental conditions (temperature of $25 \pm 2^{\circ} \mathrm{C}$, relative humidity of $75 \pm 10 \%$ and white light with photoperiod of $14: 10 \mathrm{~h}$ ).

The BmMNPV inoculum was obtained from B. mori larvae isolated in Paraná State, Brazil (Brancalhão, 2002). The viral polyhedron suspension to be administered was quantified using a Neubauer counting chamber. The concentration was adjusted to $1.8 \times 10^{6} \mathrm{OBs} / \mathrm{mL}$ (polyhedral occlusion bodies $/ \mathrm{mL}$ ).

When the larvae reached the 5th instar, the inoculations were carried out $24 \mathrm{~h}$ after ecdysis. The larvae were fed mulberry leaf disks $(2 \mathrm{~cm}$ in diameter), previously pulverized with $30 \mu \mathrm{L}$ BmMNPV viral suspension, and the control group was fed leaf disks containing filtered water. After feeding, the larvae were transferred to boxes properly identified, where they received daily mulberry leaves without BmMNPV.

Seven days after inoculation, the larval silk glands were dissected and stored in absolute isopropanol at $-20^{\circ} \mathrm{C}$.

\section{Silk gland DNA extraction}

The individual DNA samples were extracted, and since the silk glands were stored in isopropanol at $-20^{\circ} \mathrm{C}$, they were washed with $0.7 \% \mathrm{NaCl}$. The protocol was based on that described by Monesi et al. (1998) with some modifications. Briefly, the silk glands were cut up with scissors, lysed with $1 \mathrm{~mL}$ lysis buffer (50 mM Tris-HCl, pH 8.0; 50 mM EDTA, pH 8.0; $1.5 \%$ sarcosyl; $10 \mathrm{mM} \mathrm{NaCl}$, and $1 \mathrm{mg} / \mathrm{mL}$ proteinase $\mathrm{K}$ ), at $60^{\circ} \mathrm{C}$ for $3 \mathrm{~h}$ and extracted with phenol/chloroform as described by Sambrook and Russell (2001).

\section{Baculovirus DNA extraction}

DNA extraction of BmMNPV was carried out according to the protocol proposed by Yang et al. (1997), with some modifications. Infected larvae (45) were macerated in distilled water, and the solution was filtered several times until it was a milky white liquid. Subsequently, $1 \mathrm{~mL}$ of this solution was homogenized with $10 \%$ TESP buffer $(50 \mathrm{mM}$ Tris- $\mathrm{HCl}$, $\mathrm{pH} 8.5 ; 10 \mathrm{mM}$ EDTA, pH 8.0; $100 \mathrm{mM} \mathrm{NaCl} ; 1 \mathrm{mM} \mathrm{PMSF}$ ), and then centrifuged at $6500 \mathrm{~g}$ for $10 \mathrm{~min}$ at $4{ }^{\circ} \mathrm{C}$. The pellet was resuspended in two volumes of TESP, containing $1 \%$ Triton $\mathrm{X}-100$, and centrifuged again. The pellet was resuspended with TESP, followed by centrifugation, and then resuspended in TMP buffer $\left(100 \mathrm{mM}\right.$ Tris- $\mathrm{HCl}, \mathrm{pH} 7.5 ; 10 \mathrm{mM} \mathrm{MgCl}_{2} ; 1 \mathrm{mM}$ PMSF) and treated with DNAse and RNAse. The solution was incubated at $37^{\circ} \mathrm{C}$ for 15 min. Next, $30 \mathrm{~mL}$ TESP buffer was added to this solution and another centrifuged step was carried out. The final pellet was resuspended in $1 \mathrm{~mL}$ TESP. In this first step, BmMNPV nucleocapsids were obtained, free of $B$. mori RNA and DNA. In order to purify the viral DNA, a solution containing nucleocapsids was lysed with $2 \mathrm{~mL}$ GTE buffer (6 M guanidine; $50 \mathrm{mM}$ Tris- $\mathrm{HCl}$; 
$10 \mathrm{mM}$ EDTA, $\mathrm{pH}$ 7.0, which was mixed and centrifuged). The pellet was resuspended in 3 $\mathrm{mL}$ TE buffer (1.0 mM Tris-HCl, $\mathrm{pH} 7.4$, and $0.1 \mathrm{mM}$ EDTA, $\mathrm{pH} 8.0$ ) also containing $0.5 \%$ SDS and $0.5 \mathrm{mg} / \mathrm{mL}$ proteinase $\mathrm{K}$, incubated overnight at $55^{\circ} \mathrm{C}$ and extracted using the phenol/chloroform standard procedure.

The viral DNA was obtained by precipitation with $0.2 \mathrm{M} \mathrm{NaCl}$ and 7 volumes of isopropanol and resupended in $0.1 \mathrm{X}$ TE.

\section{BmMNPV ORF10 and ORF14 amplification, cloning and sequencing}

BmMNPV ORF10 and ORF14 were amplified using primers (synthesized by Alpha DNA) with known sequences of BmNPV virus (Gomi et al., 1999) (Table 1). The amplification was carried out with a final volume of $15 \mu \mathrm{L}$, with $1 \mathrm{X}$ Taq polymerase buffer (Invitrogen $\left.^{\circledR}\right), 0.75 \mathrm{mM} \mathrm{MgCl}_{2}, 200 \mu \mathrm{M}$ dNTPs and $0.8 \mu \mathrm{M}$ of each primer, $1 \mathrm{U}$ Taq DNA polymerase $\left(\right.$ Invitrogen $^{\circledR}$ ) and $20 \mathrm{ng}$ genomic DNA. The amplification reaction was performed in a Mastercycler gradient thermocycler (Eppendorf ${ }^{\circledR}$ ) using a denaturation step of $94^{\circ} \mathrm{C}$ for $60 \mathrm{~s}$, followed by 35 cycles of $94^{\circ} \mathrm{C}$ for $60 \mathrm{~s}, 63^{\circ} \mathrm{C}$ for $60 \mathrm{~s}$ and $72^{\circ} \mathrm{C}$ for $60 \mathrm{~s}$. A final extension step at $72^{\circ} \mathrm{C}$ for $30 \mathrm{~min}$ was then used. The amplification reactions were repeated at least twice.

\begin{tabular}{ll}
\multicolumn{1}{c}{ Table 1. Primers used in this study. } \\
\hline Primers & \multicolumn{1}{c}{ Primer sequence (5' $\left.\rightarrow 3^{\prime}\right)$} \\
\hline ORF10 Forward & GCATTTGAGGATGCCGGGAC \\
ORF10 Reverse & ACTGCGTTTACCACGACGAG \\
ORF14 Forward (1) & ATGGACGGTGTAAAGTTGCTG \\
ORF14 Reverse (1) & TCAAAATCAACGCCGTCGTC \\
ORF14 Forward (2) & GAAGACAGCATTTCAAGCAACG \\
ORF14 Reverse (2) & GCAATTTGTACGCTTGCGAC \\
ORF14 Forward (3) & ACAACCAAAACCGCATGTGG \\
ORF14 Reverse (3) & ACGGACACGTTCGTGTTTGG \\
ORF14 Forward (4) & TCGTGTACGGCATGTGCGAC \\
ORF14 Reverse (4) & TGTCGTCTTGCGAGTCTTCG \\
ORF14 Forward (5) & GATTACACATCGGCGTCTCAG \\
ORF14 Reverse (5) & AGGCCCAGCCAGCGGTTTAC \\
\hline
\end{tabular}

The specific band of 402 nucleotides obtained by viral genomic DNA amplification with primers relating to ORF10 was recovered on a 1.5\% agarose gel, using the MinElute Gel Extraction Kit (Qiagen $\left.{ }^{\circledR}\right)$ according to manufacturer instructions and cloned with pGEM-TEasy vector.

The ORF14 amplified products of 441, 520, 520, 513, and $595 \mathrm{bp}$, which correspond to the first, second, third, fourth, and fifth primer pairs, respectively, were individually cloned with pGEM-T-Easy vector. The recombinant DNA of these clones are called BmORF10, BmORF14-1, BmORF14-2, BmORF14-3, BmORF14-4, and BmORF14-5. The transformation was carried out with Escherichia coli strain DH5a bacteria by thermal shock (Sambrook and Russell, 2001). The clones were purified using the QIAprep Spin Miniprep Kit (Qiagen ${ }^{\circledR}$ ).

The sequencing reaction consisted of the use of the DYEnamic ET Dye Terminator Kit (Amersham-GE ${ }^{\circledR}$ ) with 400-500 ng plasmid. Sequencing was performed on automatic sequencer MegaBACE 1000 (GE Healthcare $\left.{ }^{\circledR}\right)$. The sequences were analyzed in relation to homology and identity in biological databanks, such as EMBL (EBI) (http://www.ebi.ac.uk/embl/), ExPASy 
Proteomics (http://www.expasy.ch/) and GenBank (http://www.ncbi.nlm.nih.gov/).

The amino acid sequence alignment of ORF10 of BmMNPV was carried out using the ClustalW2 program (Thompson et al., 1997) and the sequences from BmNPV isolate K4 (AF247684), BmNPV isolate T3 (L33180), BmNPV Zhenjiang strain (AF533973), BmNPV Xuwen strain (AF536206), BmNPV 10-kDa protein (S76783), BmNPV isolate K3 (AF247683), BmNPV isolate K1 (AF247681), and Autographa californica NPV p10 gene (M10023).

Similarly, an alignment of sequences referring to ORF14 from BmMNPV was performed with BmNPV isolate T3 (L33180), A. californica MNPV clone C6 (AcMNPV, L22858), Rachiplusia or MNPV (RoMNPV, AY145471), Plutella xylostella MNPV isolate CL3 (PxMNPV, DQ457003), and Maruca vitrata MNPV (MvMNPV, EF125867). The amino acid composition was calculated using Pep-Info (www.ebi.ac.uk/servicestmp/.html) and the ProtParam (http://www.expasy.ch/tools/protparam.html) software. Hydropathy plots were obtained using the Bioedit program on the Hopp and Woods (1981) scale. In order to find the possible transmembrane domains in the BmMNPV ORF14 protein, the TMHMM server 2.0 tool (http://www.cbs.dtu.dk/services/TMHMM-2.0) was used, and to verify the presence of N-terminal signal peptides the SignalP 2.0 prediction server (Nielsen et al., 1997) was used (http://www.cbs.dtu.dk/services/SignalP).

\section{RESULTS AND DISCUSSION}

\section{BmMNPV DNA}

To verify that the isolated BmMNPV DNA fraction was free from B. mori DNA, the DNA isolated from infected and control B. mori silk glands and baculovirus isolated DNA were amplified with the BmORF14-1 primer pair and B. mori actin gene (Figure 1). In the BmMNPV DNA, only the 441-bp fraction from ORF14-1 primer pair is detected (Figure 1, lane 4 ), and the fraction consisting of $\sim 800 \mathrm{bp}$ from the $B$. mori actin gene is not detected (Figure 1, lane 1), which confirms that our baculovirus fraction was not contaminated with the $B$. mori DNA. The silk gland DNA from infected (Figure 1, lanes 2 and 5) and control $B$. mori (Figure 1, lanes 3 and 6) confirms that the BmORF14-1 primer pair is exclusive for the baculovirus genome.

\section{ORF14 sequence analysis}

Pereira et al. (2008) had previously detected, from silk gland DNA from infected $B$. mori larva, a partial sequence of BmMNPV ORF14, which was amplified by RAPD primer in studies related to resistance and susceptibility of B. mori to this nucleopolyhedrovirus. In order to confirm this sequence, which was detected with an RAPD primer, specific primers were designed for ORF14 through a known sequence from BmNPV genome (Gomi et al., 1999).

The amplified products were cloned and sequenced. The analysis of ORF14 nucleotide sequence revealed that the sequence of MNPV subgroup of B. mori (BmMNPV) had identity equivalent to $99,94,93,89,79 \%$, respectively, with: BmNPV genome, isolate T3 (Gomi et al., 1999); AcMNPV genome, clone C6 (Ayres et al., 1994); PxMNPV genome, isolate CL3 (Harrison and Lynn, 2007); RoMNPV genome (Harrison and Bonning, 2003), and MvMNPV genome (Chen et al., 2008). 


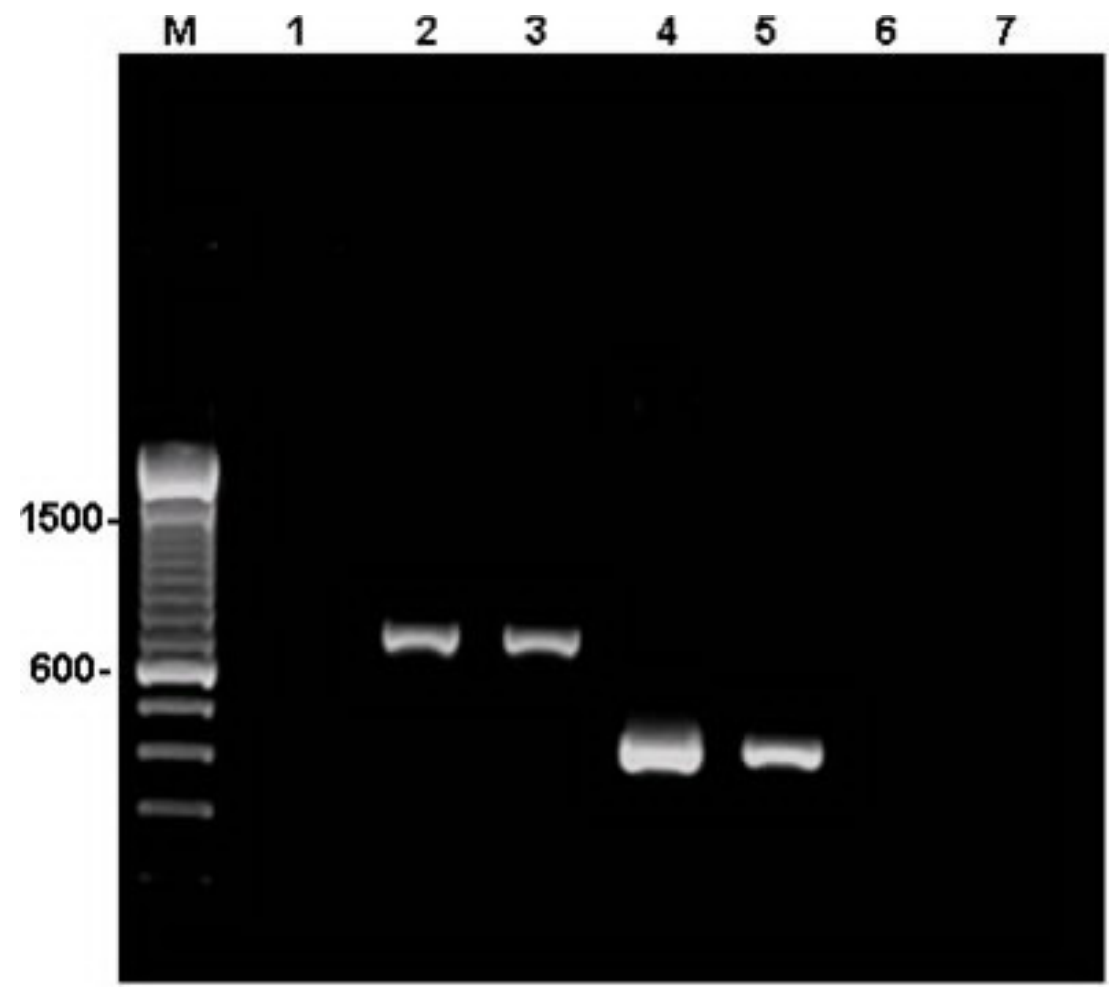

Figure 1. Bombyx mori multiple nucleopolyhedrovirus (BmMNPV) DNA qualitative analysis. To test the purified viral DNA, partial amplifications of the B. mori Actin A3 gene (lanes 1 to 3) and of ORF14 (BmORF14-1, lanes 4 to 6 ) were done. BmMNPV DNA (lanes 1 and 4), nucleopolyhedrovirus inoculated B. mori DNA (lanes 2 and 5) and control B. mori DNA (lanes 3 and 6). Lane 7, PCR negative control. 1.5\% agarose gel. $\mathrm{M}=100 \mathrm{bp}$; Invitrogen.

The ORF14 sequence was shown to be conserved in BmMNPV when compared to the BmNPV sequence. This fact indicates that the differences demonstrated by the sequencing of the polymorphic band found by RAPD primer in studies carried out by Pereira et al. (2008), could be due to errors induced by the RAPD low stringency amplification protocol.

\section{BmMNPV ORF10 and ORF14 amino acid sequences}

The analysis of BmMNPV ORF10 protein sequence showed no difference in the amino acid sequence of the BmNPV isolate $\mathrm{K} 4$ (Hong et al., 2000), BmNPV isolate T3 (Gomi et al., 1999), BmNPV Zhenjiang strain (Jiang et al., 2008), and BmNPV Xuwen strain (Jiang et al., 2008). The number of coded amino acids for p10 gene could vary among different isolates of nucleopolyhedrovirus and in different species of Lepidoptera. There are some isolates that show 70 amino acid residues, whereas others show 94 (Figure 2; Hong et al., 2000). 


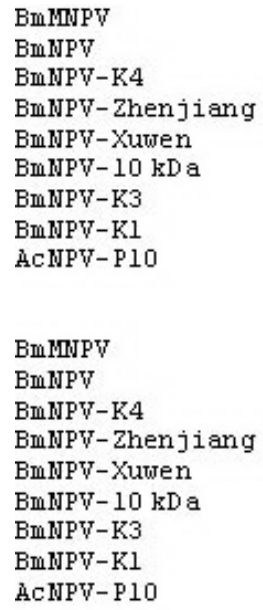

Figure 2. Bombyx mori multiple nucleopolyhedrovirus (BmMNPV) ORF10 protein sequence. Alignment of amino acid sequences of ORF10 from multiple nucleopolyhedrovirus subgroup of $B$. mori using the ClustalW2 software (EMBL-EBI). The sequences were: B. mori nucleopolyhedrovirus isolate K4 (AF247684); isolate T3 (L33180); Zhenjiang strain (AF533973); Xuwen strain (AF536206); 10-kDa protein (S76783); isolate K3 (AF247683); isolate K1 (AF247681), and Autographa californica nucleopolyhedrovirus p10 gene (M10023).

The BmNPV ORF10 sequence has been previously analyzed by Hu et al. (1994). This sequence codes for a protein of 70 amino acids that is not essential for viral replication. A study by Williams et al. (1989), which involved infected cells with AcMNPV mutated in p10 protein, suggests that this protein may be related to infected cell lysis or more precisely to nucleus disintegration (Acharya and Gopinathan, 2001).

The BmMNPV ORF14 codes for the same sequence of amino acids from BmNPV, but displays amino acid modifications (Figure 3). The sequence that belongs to the ORF14 from BmMNPV had an identity of $99 \%$ with ORF 23 of AcMNPV, which is related to viral folding protein (Gomi et al., 1999). It also had an identity of $88 \%$ with folding protein or $\mathrm{F}$ protein of PxMNPV (Harrison and Lynn, 2007), and with a folding protein of A. californica as well (Ayres et al., 1994). However, an identity of $84 \%$ was observed with a fusion protein of RoMNPV (Harrison and Bonning, 2003), whereas a 65\% identity to MvMNPV was detected (Chen et al., 2008).

The AcMNPV ORF23 protein is not essential for viral replication (Lung et al., 2003), but is a very important structural protein, since it provides the virus entrance into the host cell. In AcMNPV, this protein is found in budded virus, which is responsible for host systemic infection. Hence, the evolution and sequence alteration of these folding proteins could dramatically affect the process of virus entrance.

Mutations in ORF23 of the AcMNPV alter the number of nucleocapsids per virion, increasing the presence of the single nucleocapsid, where the death of the insect occurs more slowly (Yu et al., 2009). Packing of multiple nucleocapsids suggests a selective advantage of baculoviruses that are MNPV in relation to the single nucleocapsid per virion (Washburn et al., 2003).

This type of protein is present in the family Baculoviridae from the Nucleopolyhedrovirus genera. However, protein $\mathrm{F}$ is present in the Granulovirus genera and has a similar function as viral protein GP64 (Garry and Garry, 2008). 


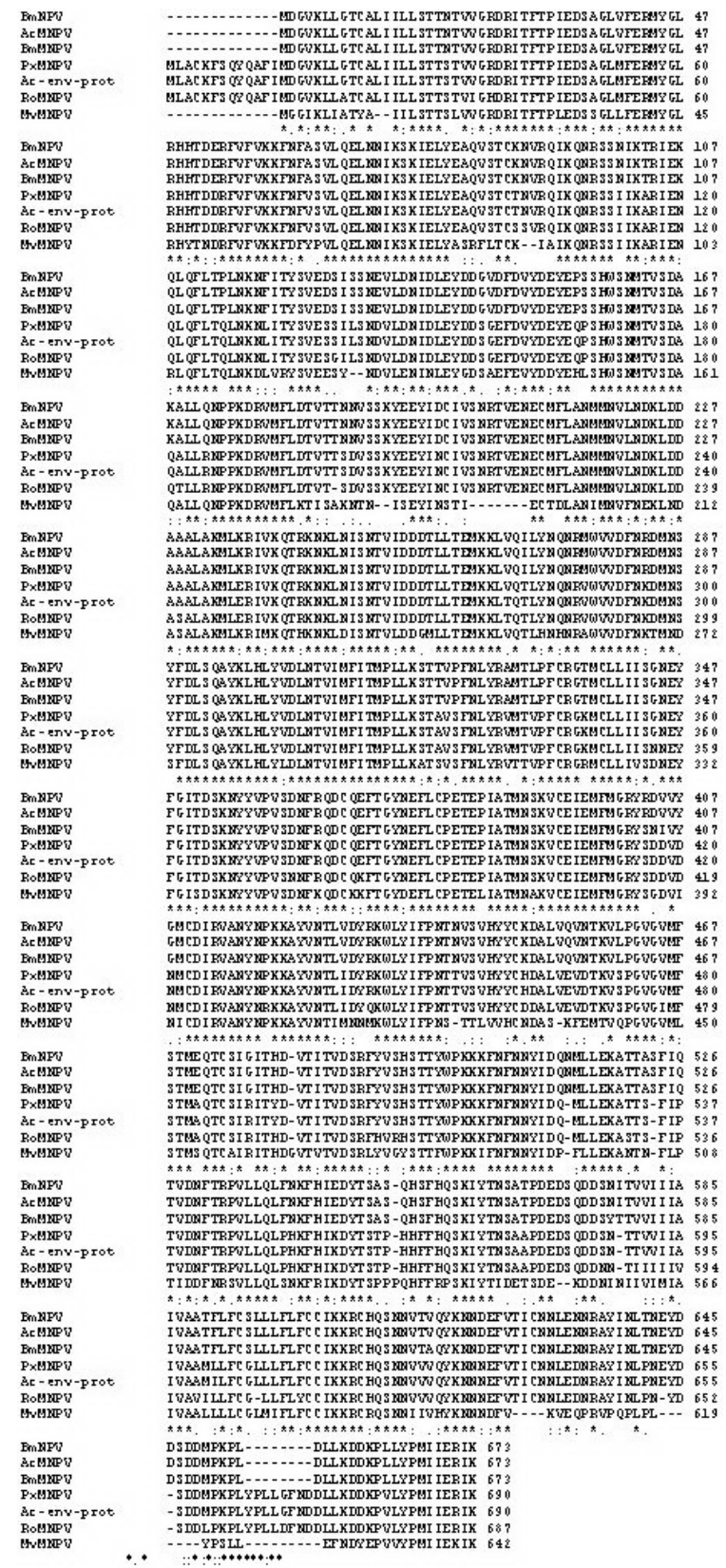

Figure 3. Bombyx mori multiple nucleopolyhedrovirus (BmMNPV) ORF14 protein sequence. Alignment of BmMNPV ORF14 amino acid sequences using the ClustalW2 software (EMBL-EBI) (e-value corresponding to 0.0 ). The sequences were: B. mori nucleopolyhedrovirus, BmNPV (L33180); Autographa californica multiple nucleopolyhedrovirus C6 clone, AcMNPV (NP047428); Plutella xylostella multiple nucleopolyhedrovirus, PxMNPV (YP758489); A. californica proteic envelope, Ac-env-prot (NP054052); Rachiplusia or multiple nucleopolyhedrovirus, RoMNPV (NP703013), and Maruca vitrata multiple nucleopolyhedrovirus, MvMNPV (YP950744). 
Viral fusion proteins are present in viruses such as human immunodeficiency virus (HIV) and flu virus (Influenza spp) as well (Jing et al., 2008). These proteins allow the entrance of folded viruses, which have a coat based on a lipid bilayer, into the cells that they infect. The exposure of fusion proteins from flu virus or HIV to low $\mathrm{pH}$ and membrane receptors of targeted cells, respectively, reveals hydrophobic regions that are called fusion peptides, which are inserted directly into the hydrophobic center of the lipid bilayer of the targeted membrane (Jing et al., 2008).

Another mechanism of virus entrance into the host cell often studied is that of Rhabdovirus, which affects a broad range of animal hosts (such as insects, fishes, mammals, and humans) but also the plant kingdom. The viruses of this genus possess a glycoprotein $\mathrm{G}$, which has in its sequence two to three regions with consecutive repetitions of seven hydrophobic amino acids, followed by positively charged amino acids (Carneiro et al., 2002). All these repeated sequences of hydrophobic amino acids are related to viral fusion in cell membranes. Part of this glycoprotein $\mathrm{G}$ (residues from 421 to 461), which includes ectodomain and transmembrane regions, could potentiate the fusion activities between the membranes (Jeetendra et al., 2003).

Similar sequences were found in the amino acid residues from BmMNPV ORF14 (amino acids 212-225, 228-239, 306-316, and 580-607; Figure 3). If the entrance of nucleopolyhedrovirus into B. mori cells occurs as with glycoprotein $\mathrm{G}$ in Rhabdovirus, further analysis should be done to verify this point.

The genetic distance related to the protein produced by ORF14 of BmMNPV, when compared to proteins of higher identity (Figure 3), was graphically represented (Figure 4) in a dendogram (Saitou and Nei, 1987), which revealed a closer correlation between BmNPV and AcMNPV proteins. The proteins are referred to as F proteins and have a similar role as GP64, which plays a role in the process of membrane fusion and is present in budded viruses, which enter the host cells via endocytosis (Garry and Garry, 2008).

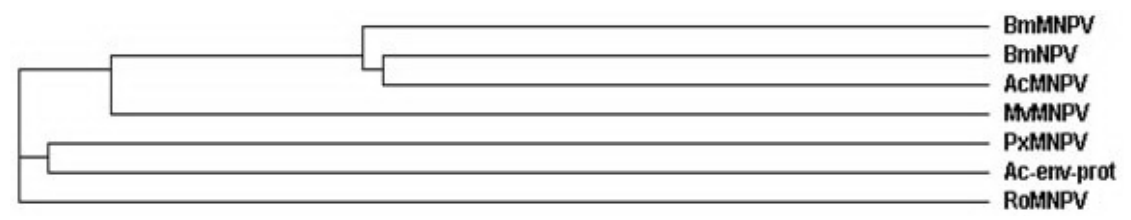

Figure 4. Phylogenetic tree using neighbor-joining method to Bombyx mori multiple nucleopolyhedrovirus (BmMNPV) ORF14 protein. For abbreviations, see legend to Figure 3.

\section{BmMNPV and BmNPV ORF14}

The BmMNPV and BmNPV ORF14 protein sequences were analyzed in silico in relation to their molecular mass, isoelectric point and signaling peptide. The gene attributed to ORF14 consists of 2022 nucleotides that code for a protein of 673 amino acids. Using the ProtParam program (http://www.expasy.ch/tools/protparam.html), the molecular mass for BmMNPV and BmNPV was estimated at 77,905 and 77,952, respectively, a probable isoelectric point of 5.47 was determined for both, as well as a signaling peptide of 24 residues was found. BmMNPV and BmNPV ORF14 were analyzed by the ProtFun 2.2 software, and the data related to protein localization and their differences were predicted (Jiang et al., 2005). This analysis (Table 2) demonstrated that both BmNPV and BmMNPV ORF14 probably code for a membrane protein that could be involved in fusion or the endocytosis process, providing the virus entrance into the 
host cell. When the amino acid sequence was analyzed in order to predict the gene category, it was assumed that it could be involved with a stress response (Table 3). This could happen at the moment when the production of this protein is essential for the Nucleopolyhedrovirus life cycle.

Table 2. Comparison between the protein of ORF14 from Bombyx mori multiple nucleopolyhedrovirus (BmMNPV) and B. mori nucleopolyhedrovirus (BmNPV) in agreement with the probable function.

\begin{tabular}{|c|c|c|c|c|}
\hline \multirow[t]{2}{*}{ Functional category } & \multicolumn{2}{|c|}{ BmMNPV } & \multicolumn{2}{|c|}{ BmNPV } \\
\hline & Prob & Odds & Prob & Odds \\
\hline Amino acid biosynthesis & 0.014 & 0.623 & 0.014 & 0.625 \\
\hline Biosynthesis of cofactors & 0.073 & 1.011 & 0.069 & 0.962 \\
\hline Cell envelope* & 0.804 & 13.186 & 0.804 & 13.186 \\
\hline Cellular processes & 0.031 & 0.420 & 0.031 & 0.420 \\
\hline Central intermediary metabolism & 0.219 & 3.471 & 0.213 & 3.381 \\
\hline Energy metabolism & 0.030 & 0.328 & 0.030 & 0.328 \\
\hline Fatty acid metabolism & 0.016 & 0.265 & 0.016 & 1.265 \\
\hline Purines and pyrimidines & 0.569 & 2.341 & 0.568 & 2.339 \\
\hline Regulatory functions & 0.013 & 0.080 & 0.013 & 0.080 \\
\hline Replication and transcription & 0.019 & 0.073 & 0.019 & 0.073 \\
\hline Translaction & 0.036 & 0.816 & 0.036 & 0.816 \\
\hline Transport and binding & 0.834 & 2.033 & 0.833 & 2.032 \\
\hline
\end{tabular}

*Indicates the probable functional category of the protein.

Table 3. Comparison of the protein of ORF14 from Bombyx mori multiple nucleopolyhedrovirus (BmMNPV) and $B$. mori nucleopolyhedrovirus (BmNPV) in agreement with the probable gene category.

\begin{tabular}{|c|c|c|c|c|}
\hline \multirow[t]{2}{*}{ Gene category } & \multicolumn{2}{|c|}{ BmMNPV } & \multicolumn{2}{|c|}{ BmNPV } \\
\hline & Prob & Odds & Prob & Odds \\
\hline Signal transducer & 0.167 & 0.780 & 0.172 & 0.802 \\
\hline Receptor & 0.156 & 0.916 & 0.163 & 0.958 \\
\hline Hormone & 0.001 & 0.206 & 0.001 & 0.206 \\
\hline Structural protein & 0.011 & 0.411 & 0.013 & 0.458 \\
\hline Transporter & 0.024 & 0.217 & 0.024 & 0.217 \\
\hline Ion channel & 0.008 & 0.148 & 0.008 & 0.148 \\
\hline Voltage gated ion channel & 0.002 & 0.097 & 0.002 & 0.099 \\
\hline Cation channel & 0.010 & 0.215 & 0.010 & 0.215 \\
\hline Transcription & 0.030 & 0.235 & 0.030 & 0.236 \\
\hline Transcription regulation & 0.021 & 0.166 & 0.021 & 0.165 \\
\hline Stress response* & 0.156 & 1.770 & 0.171 & 1.940 \\
\hline Immune response & 0.063 & 0.741 & 0.045 & 0.530 \\
\hline Growth factor & 0.043 & 3.052 & 0.043 & 3.052 \\
\hline Metal ion transport & 0.012 & 0.026 & 0.012 & 0.025 \\
\hline
\end{tabular}

*Indicates the probable functional category of the protein.

Similar predicting gene structure analyses were carried out in several studies involving human proteins from the MHC complex (Jiang et al., 2005) and baculovirus GP64 protein as well (Garry and Garry, 2008).

Upon analysis of the primary protein structure in relation to cellular membrane, in which it is probably inserted, a transmembrane helix that was conserved in all baculoviral proteins was predicted (Figure 5). The transmembrane helix region was located between amino acids 580 and 602, where it is considered to be a sequence rich in hydrophobic amino acids that are close to C-terminal region of the protein. 

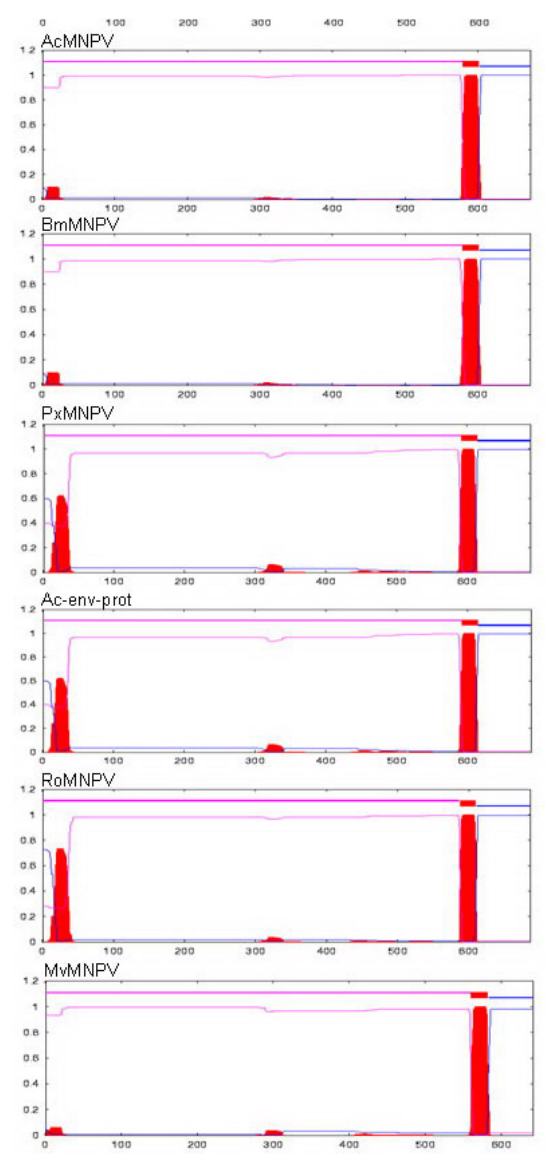

Figure 5. Baculoviral ORF14 potential transmembrane domains. The amino acid residue numbers are positioned on the $\mathrm{x}$-axis and the existence probability of transmembrane domains are on the y-axis. For abbreviations, see legend to Figure 3.

The transmembrane helix analysis was conducted by Garry and Garry (2008) in order to describe GP64, a baculoviral protein that has a C-terminal transmembrane region rich in hydrophobic amino acids, similar to the one found in our analysis.

Likely, the vesicular stomatitis virus has a region, called glycoprotein $\mathrm{G}$, that acts as a receptor, promoting the viral envelop fusion with the host cell membrane through a low $\mathrm{pH}$, followed by the endocytosis process (Jeetendra et al., 2003). This region is also rich in hydrophobic amino acids, but when mutations (insertions and deletions) are detected, there is also a reduction in host cell fusion activity. The inactivation of viruses occurs with diethylpyrocarbonate, where histidine residues present in protein $\mathrm{G}$ are modified (Stauffer et al., 2007).

Regions with hydrophobic amino acids that are located in the transmembrane domain of virus proteins, are usually involved in the process of fusion between cellular membranes. These highly hydrophobic regions that encompass membrane-spanning regions are present in other baculoviral proteins (Figure 5), where there is little difference in hydrophobicity between the compared sequences. 
In the region related to the amino acid in position 400 , there is a hydrophobicity variation among the sequences, in which BmNPV exhibits residues more hydrophobic, but shares similarity with proteins from other baculoviruses (Figure 6). The C-terminal region of the protein also shows variations. Hydrophobicity parameters are important because they affect the interactions between molecules and their linkages. Not only hydrophobicity, but also factors such as $\mathrm{pH}$ and transmembrane do-

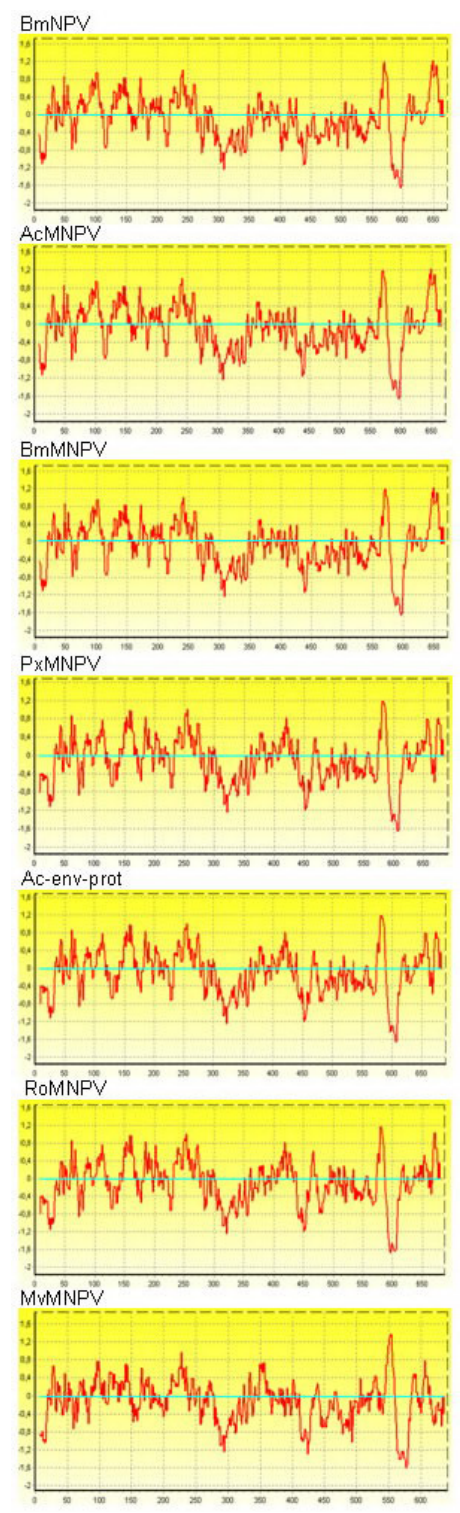

Figure 6. Comparison of the BmMNPV ORF14 hydrophilicity plots with BmNPV, AcMNPV, PxMNPV, Ac-env-prot, RoMNPV, and MvMNPV. Positive values indicate hydrophilic areas, whereas negative values indicate hydrophobic areas. Data obtained from the Bioedit program on the Hoop-Woods scale. For abbreviations, see legend to Figure 3. 
mains are involved in the process of cellular adhesion. In addition, coronaviruses (Kanjanahaluethai et al., 2007) show a transmembrane structure that has a sequence of hydrophobic amino acids that works as in vesicular stomatitis virus. Thus, at low $\mathrm{pH}$, it activates the fusion between the cell membranes.

Several studies have been carried out with baculoviruses with the objective of characterizing genes and identifying their functions. The data presented in this paper provide evidence that proteins produced by ORFs 10 and 14 from BmNPV and BmMNPV are highly conserved proteins in NPVs and MNPVs. The high degree of conservation, between members of these genera, indicates the importance of these proteins, and could translate to a possibly significant function, which is active throughout the infection cycle.

\section{ACKNOWLEDGMENTS}

Research supported by grants from FINEP/Fundação Araucária, Secretaria de Estado da Ciência, Tecnologia e Ensino Superior, SETI, FUNDO PARANA, Academy of Sciences for Developing World - TWAS, and Science and Innovation Santander Banespa 2006 Prize. S.A. Santos received a graduate fellowship from CAPES. We also thank Valmir Peron and Marli Licero Schuete Silva for their dedicated technical assistance and the Universidade Estadual de Maringá for the facilities (COMCAP laboratories). We are grateful to Pedrina Gonçalves Vidigal for help with the grammatical revision of the manuscript.

\section{REFERENCES}

Acharya A and Gopinathan KP (2001). Identification of an enhancer-like element in the polyhedrin gene upstream region of Bombyx mori nucleopolyhedrovirus. J. Gen. Virol. 82: 2811-2819.

Acharya A, Sriram S, Sehrawat S, Rahman M, et al. (2002). Bombyx mori nucleopolyhedrovirus: molecular biology and biotechnological applications for large-scale synthesis of recombinant proteins. Curr. Sci. 83: 455-465.

Ayres MD, Howard SC, Kuzio J, Lopez-Ferber M, et al. (1994). The complete DNA sequence of Autographa californica nuclear polyhedrosis virus. Virology 202: 586-605.

Blissard GW (1996). Baculovirus - insect cell interactions. Cytotechnology 20: 73-93.

Brancalhão RMC (2002). Vírus entomopatogênicos no bicho da seda. Biotecnol. Cienc. Desenvolv. 24: 54-58.

Carneiro FA, Bianconi ML, Weissmuller G, Stauffer F, et al. (2002). Membrane recognition by vesicular stomatitis virus involves enthalpy-driven protein-lipid interactions. J. Virol. 76: 3756-3764.

Chen YR, Wu CY, Lee ST, Wu YJ, et al. (2008). Genomic and host range studies of Maruca vitrata nucleopolyhedrovirus. J. Gen. Virol. 89: 2315-2330.

Garry CE and Garry RF (2008). Proteomics computational analyses suggest that baculovirus GP64 superfamily proteins are class III penetrenes. Virol. J. 5: 28.

Gomi S, Majima K and Maeda S (1999). Sequence analysis of the genome of Bombyx mori nucleopolyhedrovirus. J. Gen. Virol. 80 (Pt 5): 1323-1337.

Harrison RL and Bonning BC (2003). Comparative analysis of the genomes of Rachiplusia ou and Autographa californica multiple nucleopolyhedroviruses. J. Gen. Virol. 84: 1827-1842.

Harrison RL and Lynn DE (2007). Genomic sequence analysis of a nucleopolyhedrovirus isolated from the diamondback moth, Plutella xylostella. Virus Genes 35: 857-873.

Hawtin RE, Zarkowska T, Arnold K, Thomas CJ, et al.(1997). Liquefaction of Autographa californica nucleopolyhedrovirusinfected insects is dependent on the integrity of virus-encoded chitinase and cathepsin genes. Virology 238: 243-253.

Hayakawa T, Rohrmann GF and Hashimoto Y (2000). Patterns of genome organization and content in lepidopteran baculoviruses. Virology 278: 1-12.

Hong HK, Woo SD, Choi JY, Lee HK, et al. (2000). Characterization of four isolates of Bombyx mori nucleopolyhedrovirus. Arch. Virol. 145: 2351-2361.

Hopp TP and Woods KR (1981). Prediction of protein antigenic determinants from amino acid sequences. Proc. Natl. Acad. Sci. U. S. A. 78: 3824-3828. 
Horton HM and Burand JP (1993). Saturable attachment sites for polyhedron-derived baculovirus on insect cells and evidence for entry via direct membrane fusion. J. Virol. 67: 1860-1868.

Hu NT, Lu YF, Hashimoto Y, Maeda S, et al. (1994). The p10 gene of natural isolates of Bombyx mori nuclear polyhedrosis virus encodes a truncated protein with an M(r) of 7700. J. Gen. Virol. 75 (Pt 8): 2085-2088.

Jeetendra E, Ghosh K, Odell D, Li J, et al. (2003). The membrane-proximal region of vesicular stomatitis virus glycoprotein $\mathrm{G}$ ectodomain is critical for fusion and virus infectivity. J. Virol. 77: 12807-12818.

Jiang L, Lund O and Tan JQ (2005). Selection of proteins for human MHC class II presentation. Cell Mol. Immunol. 2: 49-56.

Jiang LH, Cai PZ, Zhong WF, Xu XY, et al. (2008). Characterization of Seven Strains of Bombyx mori Nucleopolyhedrovirus. Available at [http://www.genome.ad.jp/dbget-bin/www_bget?uniprot+Q8AZ04_NPVBM]. Accessed November 1, 2008.

Jing X, Ma C, Ohigashi Y, Oliveira FA, et al. (2008). Functional studies indicate amantadine binds to the pore of the influenza A virus M2 proton-selective ion channel. Proc. Natl. Acad. Sci. U. S. A. 105: 10967-10972.

Kanjanahaluethai A, Chen Z, Jukneliene D and Baker SC (2007). Membrane topology of murine coronavirus replicase nonstructural protein 3. Virology 361: 391-401.

Khurad AM, Mahulikar A, Rathod MK, Rai MM, et al. (2004). Vertical transmission of nucleopolyhedrovirus in the silkworm, Bombyx mori L. J. Invertebr. Pathol. 87: 8-15.

Lung OU, Cruz-Alvarez MW and Blissard GW (2003). Ac23, an envelope fusion protein homolog in the baculovirus Autographa californica multicapsid nucleopolyhedrovirus, is a viral pathogenicity factor. J. Virol. 77: 328-339.

Monesi N, Jacobs-Lorena M and Paco-Larson ML (1998). The DNA puff gene BhC4-1 of Bradysia hygida is specifically transcribed in early prepupal salivary glands of Drosophila melanogaster. Chromosoma 107: 559-569.

Nielsen H, Engelbrecht J, Brunak S and von Heijne G (1997). Identification of prokaryotic and eukaryotic signal peptides and prediction of their cleavage sites. Protein Eng. 10: 1-6.

Pereira EP, Conte H, Ribeiro LF, Zanatta DB, et al. (2008). Cytopathological process by multiple nucleopolyhedrovirus in the testis of Bombyx mori L., 1758 (Lepidoptera: Bombycidae). J. Invertebr. Pathol. 99: 1-7.

Rahman MM and Gopinathan KP (2003). Characterization of the gene encoding the envelope fusion glycoprotein GP64 from Bombyx mori nucleopolyhedrovirus. Virus Res. 94: 45-57.

Saitou N and Nei M (1987). The neighbor-joining method: a new method for reconstructing phylogenetic trees. Mol. Biol. Evol. 4: 406-425.

Sambrook J and Russell DW (2001). Molecular Cloning: A Laboratory Manual. 3rd edn. Cold Spring Harbor Laboratory Press, New York.

Stauffer F, De Miranda J, Schechter MC, Queiroz FA, et al. (2007). New chemical method of viral inactivation for vaccine development based on membrane fusion inhibition. Vaccine 25: 7885-7892.

Thompson JD, Gibson TJ, Plewniak F, Jeanmougin F, et al. (1997). The CLUSTAL_X windows interface: flexible strategies for multiple sequence alignment aided by quality analysis tools. Nucleic Acids Res. 25: 4876-4882.

Torquato EF, de Miranda Neto MH, Brancalhao RM and Franco VS (2006). Nucleopolyhedrovirus: scanning electron microscopy technique. Neotrop. Entomol. 35: 787-790.

Washburn JO, Chan EY, Volkman LE, Aumiller JJ, et al. (2003). Early synthesis of budded virus envelope fusion protein GP64 enhances Autographa californica multicapsid nucleopolyhedrovirus virulence in orally infected Heliothis virescens. J. Virol. 77: 280-290.

Watanabe H (2002). Genetic resistance of the silkworm, Bombyx mori to viral diseases. Curr. Sci. 83: 439-446.

Williams GV, Rohel DZ, Kuzio J and Faulkner P (1989). A cytopathological investigation of Autographa californica nuclear polyhedrosis virus p10 gene function using insertion/deletion mutants. J. Gen. Virol. 70 (Pt 1): 187-202.

Yang F, Wang W, Chen RZ and Xu X (1997). A simple and efficient method for purification of prawn baculovirus DNA. J. Virol. Methods 67: 1-4.

Yao Q, Li MW, Wang Y, Wang WB, et al. (2003). Screening of molecular markers for NPV resistance in Bombyx mori L. (Lep., Bombycidae). J. Appl. Entomol. 127: 134-136.

Yu IL, Bray D, Lin YC and Lung O (2009). Autographa californica multiple nucleopolyhedrovirus ORF 23 null mutant produces occlusion-derived virions with fewer nucleocapsid. J. Gen. Virol. 90: 1499-1504. 